\title{
Mediterranean climate extremes in synoptic downscaling assessments
}

\author{
Stefanie Seubert • Sonia Fernández-Montes • \\ Andreas Philipp · Elke Hertig • Jucundus Jacobeit • \\ Gernot Vogt • Andreas Paxian · Heiko Paeth
}

\begin{abstract}
The behaviour of precipitation and maximum temperature extremes in the Mediterranean area under climate change conditions is analysed in the present study. In this context, the ability of synoptic downscaling techniques in combination with extreme value statistics for dealing with extremes is investigated. Analyses are based upon a set of long-term station time series in the whole Mediterranean area. At first, a station-specific ensemble approach for model validation was developed which includes (1) the downscaling of daily precipitation and maximum temperature values from the large-scale atmospheric circulation via analogue method and (2) the fitting of extremes by generalized Pareto distribution (GPD). Model uncertainties are quantified as confidence intervals derived from the ensemble distributions of GPD-related return values and described by a new metric called "ratio of overlapping". Model performance for extreme precipitation is highest in winter, whereas the best models for maximum temperature extremes are set up in autumn. Valid models are applied to a 30-year period at the end of the twenty-first century (2070-2099) by means of ECHAM5/MPI-OM general circulation model data for IPCC SRES B1 scenario. The most
\end{abstract}

S. Seubert $(\bowtie) \cdot$ A. Philipp · E. Hertig · J. Jacobeit Department of Geography, University of Augsburg, Universitätsstrasse 10, 86159 Augsburg, Germany

e-mail: stefanie.seubert@geo.uni-augsburg.de

S. Fernández-Montes

Department of Applied Physics, University of Almeria,

Almeria, Spain

A. Paxian · G. Vogt $\cdot$ H. Paeth

Department of Geography and Geology, University of Würzburg, Am Hubland, 97074 Würzburg, Germany distinctive future changes are observed in autumn in terms of a strong reduction of precipitation extremes in Northwest Iberia and the Northern Central Mediterranean area as well as a simultaneous distinct increase of maximum temperature extremes in Southwestern Iberia and the Central and Southeastern Mediterranean regions. These signals are checked for changes in the underlying dynamical processes using extreme-related circulation classifications. The most important finding connected to future changes of precipitation extremes in the Northwestern Mediterranean area is a reduction of southerly displaced deep North Atlantic cyclones in 2070-2099 as associated with a strengthened North Atlantic Oscillation. Thus, the here estimated future changes of extreme precipitation are in line with the discourse about the influence of North Atlantic circulation variability on the changing climate in Europe.

\section{Introduction}

The Mediterranean area, a region of pronounced climatic variability, is estimated to be strongly affected by future climate change. The climate projections of the last IPCC AR 4 anticipate a regional decline of precipitation averages in all seasons until the end of the twenty-first century (Salomon et al. 2007). At the same time, seasonal temperature averages will rise with maximum rates in summer reaching from 2.5 to $6.5{ }^{\circ} \mathrm{C}$ (ibid.). To know about future changes of climate is highly important for this densely populated region characterized by intensive agricultural land use, mainly with respect to water availability in summer. Moreover, the prospective evolution of precipitation and maximum temperature extremes is of particular interest for the Mediterranean region because climate extremes in regions of seasonal aridity are linked to very serious 
impacts on ecosystems and society. While several contributions focus on the variations of Mediterranean climate extremes throughout the instrumental period (e.g. Beguera et al. 2011; Kioutsioukis et al. 2010; Fernandez-Montes and Rodrigo 2011), less studies address Mediterranean extreme events in a changing future climate as for example Hertig et al. (2013) assessing future precipitation extremes with generalized linear models (GLMs): the authors detect frequency and intensity decreases mainly in the Western Mediterranean area and the Eastern Adriatic coast in spring and autumn. At the same time, precipitation extremes rise in parts of Italy, Southern France and Greece. In wintertime, widespread increases of extreme events take place until the end of the twenty-first century except for the Tunisian coastline, the Eastern Mediterranean area and parts of Turkey, where decreases are assessed.

The studies of Beniston et al. (2007) and Frei et al. (2006), analysing output from different regional climate models (RCMs) with regard to precipitation extremes on the whole European continent, also include important information about the Mediterranean area: the authors of both contributions found wintertime decreases of heavy precipitation, Beniston et al. (2007) in whole Southern Europe (south of $45^{\circ} \mathrm{N}$ ) and Frei et al. (2006) mainly in Iberia and the Central Mediterranean area. With respect to the Iberian Peninsula, this study points out that the future decline of wintertime precipitation extremes is only small and mostly non-significant (Frei et al. 2006). Furthermore, a decrease of heavy precipitation in Iberia is indicated by RCM results for the transitional seasons, whereas in some of the models, large increases of precipitation extremes in autumn are observed in the Central Mediterranean area (ibid.). In contrast, Goubanova and $\mathrm{Li}$ (2007), addressing future changes of extremes with a general circulation model (GCM) regionally zoomed to the Mediterranean area, describe increasing precipitation extremes in all seasons except summer. In summary, different and partially opposite results for the future development of precipitation extremes are obtained mainly depending on the different projection methods.

Regarding Mediterranean maximum temperature extremes in the future, an increase not only of annual means but also of annual extremes is assessed by Goubanova and Li (2007). Hertig et al. (2010) found summertime increases of maximum temperature (TMAX) extremes with a maximum of around $2{ }^{\circ} \mathrm{C}$ in the Western Mediterranean region (Iberia), whereas weak decreases dominate in parts of the Eastern Mediterranean area. Nikulin et al. (2011), focusing on European temperature extremes in RCM output, describe a rise of temperature extremes in winter and summer until the end of the twenty-first century in Southern Europe including the Western and Central Mediterranean regions. In terms of the number of annual hot days and heatwave frequencies, Beniston et al. (2007) point to a strong increase in the south of Europe and mainly the southern parts of the Mediterranean area (e.g. the south of Spain) during the twenty-first century.

In the present study, the future development of precipitation and maximum temperature extremes in the Mediterranean area is analysed by means of synoptic downscaling methods, focusing on the analogue method (Zorita and von Storch 1999), and daily resolved future GCM projections. Changes in future extreme events are described via extreme value theory providing statistical analyses related to climate extremes (Fisher and Tippett 1928; Katz 1999; Katz et al. 2002; Naveau et al. 2005). In this context, the peakover-threshold approach is chosen. It is based on identifying all events exceeding a given threshold value and fitting to the resulting extreme series a specific probability distribution, in this case the generalized Pareto distribution (Katz et al. 2002; Paeth and Hense 2005; Mares et al. 2009). Shifts in the corresponding return values provide information about the direction and magnitude of future changes. Distinct clear signals of future changes are further examined in terms of the variations of the underlying circulation mechanisms. The present study concentrates on shifts in future extremes related to changes in circulation variability described by mean sea level pressure variations. It is important to bear in mind that especially for future temperature projections, also other atmospheric and land cover changes are of importance which are not directly taken into account here (e.g. enhanced greenhouse gas concentrations, clouds, soil moisture). While many previous works show the good agreement between extreme precipitation and atmospheric circulation, extreme temperatures usually depend on further influences (e.g. SSTs, see Cattiaux et al. 2010; FernándezMontes et al. 2012). Even if those quantities probably will lead to an amplification of the projected changes (towards a warming in the case of temperature) and more intense precipitation events (Trenberth 2011), they are difficult to quantify and moreover, unlike SLP, not well represented in GCMs. Thus, in the present study, future shifts in daily extremes are solely related to circulation changes. Concerning precipitation extremes, the present results focus on the "Mediterranean rainy season"-including autumn (SON), winter (DJF) and spring (MAM). Regarding maximum temperature extremes, the extended "summer half year" is of particular interest. Hence, TMAX extremes in spring (MAM), summer (JJA) and autumn (SON) are addressed. The study is outlined as follows: Section 2 specifies the observational and model data being analysed, and Section 3 explains the applied methods of downscaling (Section 3.1), of model validation (Section 3.2) and of circulation analysis (Section 3.3). In Section 4, the results concerning model quality (Section 4.1) and future changes of precipitation and maximum temperature extremes (Section 4.2) are described. Potential reasons for changes in terms of the 
Table 1 Subgroups (first column) of stations for daily precipitation including the number of stations (third, fifth and seventh columns) and the time series length (second, fourth and sixth columns) in the Western (W-MED), Central (CMED) and Eastern (E-MED) Mediterranean regions

\begin{tabular}{llrllll}
\hline & W-MED & \multicolumn{3}{l}{ C-MED } & E-MED & \\
\hline 1. & $1871-2006$ & 9 & $1871-2002$ & 6 & $1916-2004$ & 5 \\
2. & $1900-2006$ & 10 & $1872-2008$ & 2 & $1921-2005$ & 2 \\
3. & $1910-2003$ & 2 & $1899-2002$ & 1 & $1939-2005$ & 2 \\
4. & $1941-2006$ & 11 & $1951-2008$ & 7 & $1939-2006$ & 3 \\
5. & $1941-1994$ & 4 & $1958-2008$ & 7 & $1953-1993$ & 2 \\
6. & $1949-2006$ & 5 & $1958-2000$ & 2 & $1958-2003$ & 14 \\
7. & $1950-2005$ & 6 & & & & \\
8. & $1961-2006$ & 4 & & & & \\
9. & $1961-2001$ & 2 & & & & \\
\hline
\end{tabular}

underlying circulation dynamics are discussed in Section 5, and Section 6 provides the concluding remarks.

\section{Data}

A set of long-term daily resolved precipitation and maximum temperature time series from weather stations in the Mediterranean area has been compiled from (1) the European Climate Assessment and Dataset (ECA\&D, (Klein Tank et al. 2002)) as well as from the datasets of (2) the EMULATE Project (Moberg et al. 2006) and (3) the GLOWA Jordan River Project (Kunstmann and Rimmer 2006). Altogether, 106 station series are available for precipitation and 87 for maximum temperature. To give an idea about the different series lengths, precipitation and maximum temperature stations with similar time series length are arranged into subgroups and displayed in Tables 1 and 2. The station locations in the Mediterranean area are displayed in Figs. 1 and 2 of Section 4.1. Data quality in terms of completeness and homogeneity was primarily analysed within the framework of the different projects. Additionally, homogeneity of the station time series used in this study is tested as in Wijngaard et al. (2003) applying absolute homogeneity tests for providing homogeneity flags of the daily ECA\&D datasets. Results are comparable and indicate most stations as reliable and none of the station series have been excluded. However, since absolute tests do not differ between real climate variations and inhomogeneities, these test results have to be treated with care.

As a large-scale atmospheric predictor, mean sea level pressure (MSLP) is focused. MSLP data have been taken from the 20th Century Reanalysis V2 (NCEP V2) data provided by the NOAA/OAR/ESRL PSD Boulder, Colorado (USA) from their website at http://www.esrl.noaa.gov/psd/ for calibrating and validating the statistical models.

The choice for MSLP in favour of geopotential height of higher levels, which in some cases (e.g. the summer season) might provide more predictive skill in the Mediterranean area, is motivated by the higher quality level of reconstructed MSLP data compared to mid or high tropospheric variables, which are also based on surface variables only (Compo et al. 2011). Thus, upper tropospheric data of sufficient quality are available only for periods which are too short for dealing with extremes.

Three different $2^{\circ} \times 2^{\circ}$ grids represent separate predictor domains for the Western $\left(16^{\circ} \mathrm{W}-8{ }^{\circ} \mathrm{E}\right.$ and $\left.45^{\circ} \mathrm{N}-32^{\circ} \mathrm{N}\right)$, the Central $\left(8^{\circ} \mathrm{E}-30^{\circ} \mathrm{E}\right.$ and $\left.40^{\circ} \mathrm{N}-34^{\circ} \mathrm{N}\right)$ and the Eastern Mediterranean $\left(20^{\circ} \mathrm{E}-42^{\circ} \mathrm{E}\right.$ and $\left.42^{\circ} \mathrm{N}-28^{\circ} \mathrm{N}\right)$ regions
Table 2 Subgroups (first column) of stations for daily TMAX including the number of stations (third, fifth and seventh columns) and the time series length (second, fourth and sixth columns) in the Western (W-MED), Central (CMED) and Eastern (E-MED) Mediterranean regions

\begin{tabular}{llrllll}
\hline & W-MED & \multicolumn{2}{l}{ C-MED } & E-MED & \\
\hline 1. & $1871-2003$ & 7 & $1871-1997$ & 3 & $1929-2006$ & 2 \\
2. & $1887-2003$ & 2 & $1890-2001$ & 3 & $1958-2003$ & 14 \\
3. & $1895-2003$ & 10 & $1940-2007$ & 2 & $1964-2003$ & 5 \\
4. & $1901-1994$ & 1 & $1951-2007$ & 7 & & \\
5. & $1905-2006$ & 6 & $1958-2008$ & 5 & \\
6. & $1927-2008$ & 3 & $1958-2000$ & 4 & \\
7. & $1938-2007$ & 1 & $1970-2000$ & 2 & \\
8. & $1941-1994$ & 1 & & & \\
9. & $1946-2005$ & 4 & & & \\
10. & $1949-2008$ & 2 & & & \\
11. & $1961-2008$ & 3 & & & \\
\hline
\end{tabular}



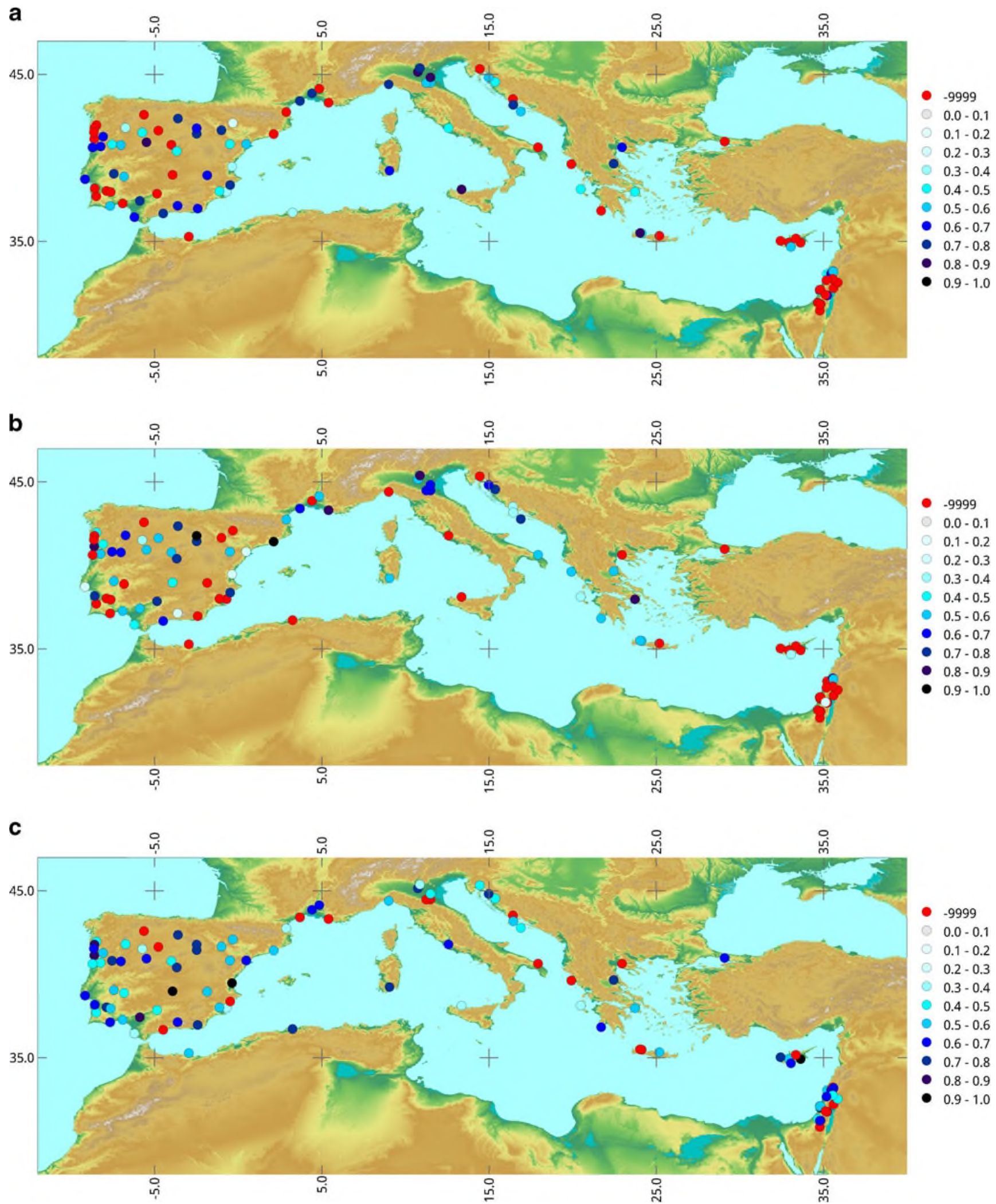

Fig. 1 Ratio of overlapping (ROO) for 30-year rainfall events in spring (a), autumn (b) and winter (c). Valid models are displayed with bright and dark blue circles and non-valid ones with red circles; see text for explanation 


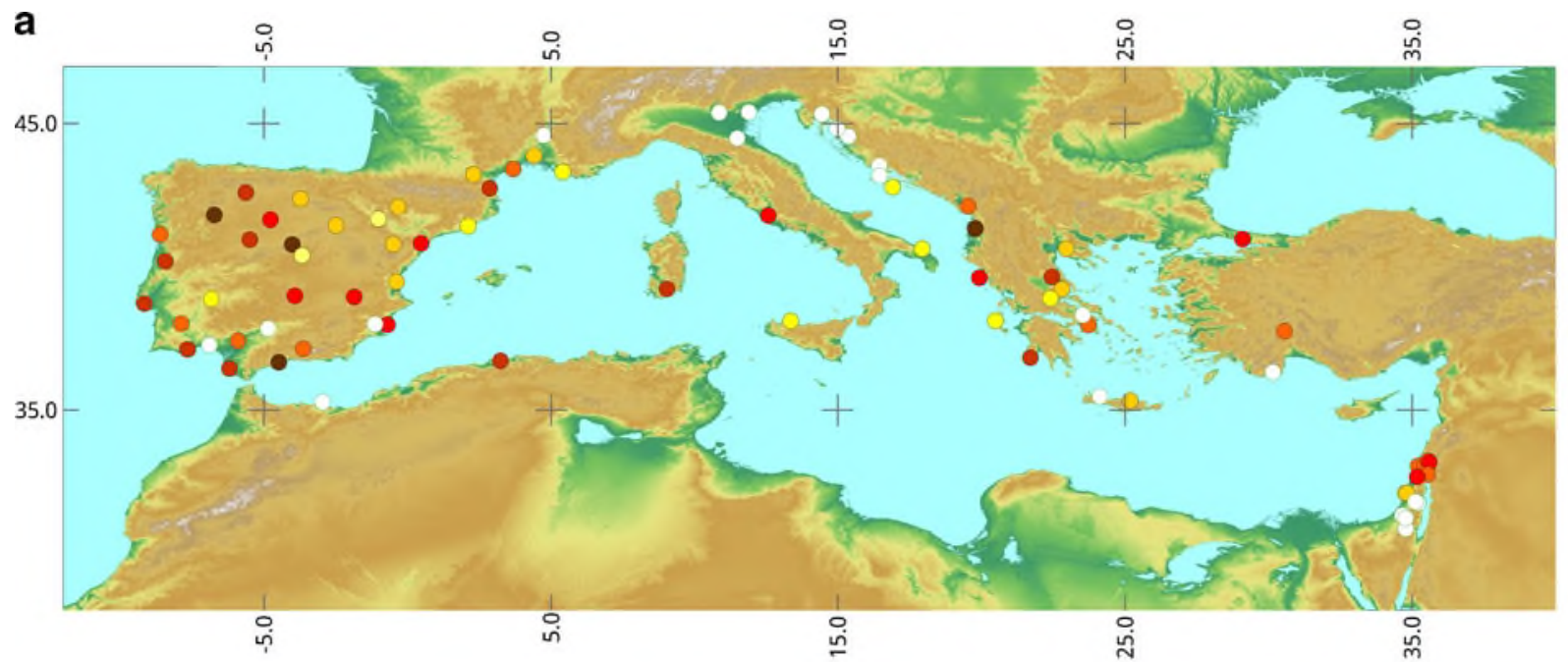

-9999
$0.0-0.1$
$0.1-0.2$
$0.2-0.3$
$0.3-0.4$
$0.4-0.5$
$0.5-0.6$
$0.6-0.7$
$0.7-0.8$
$0.8-0.9$
$0.9-1.0$

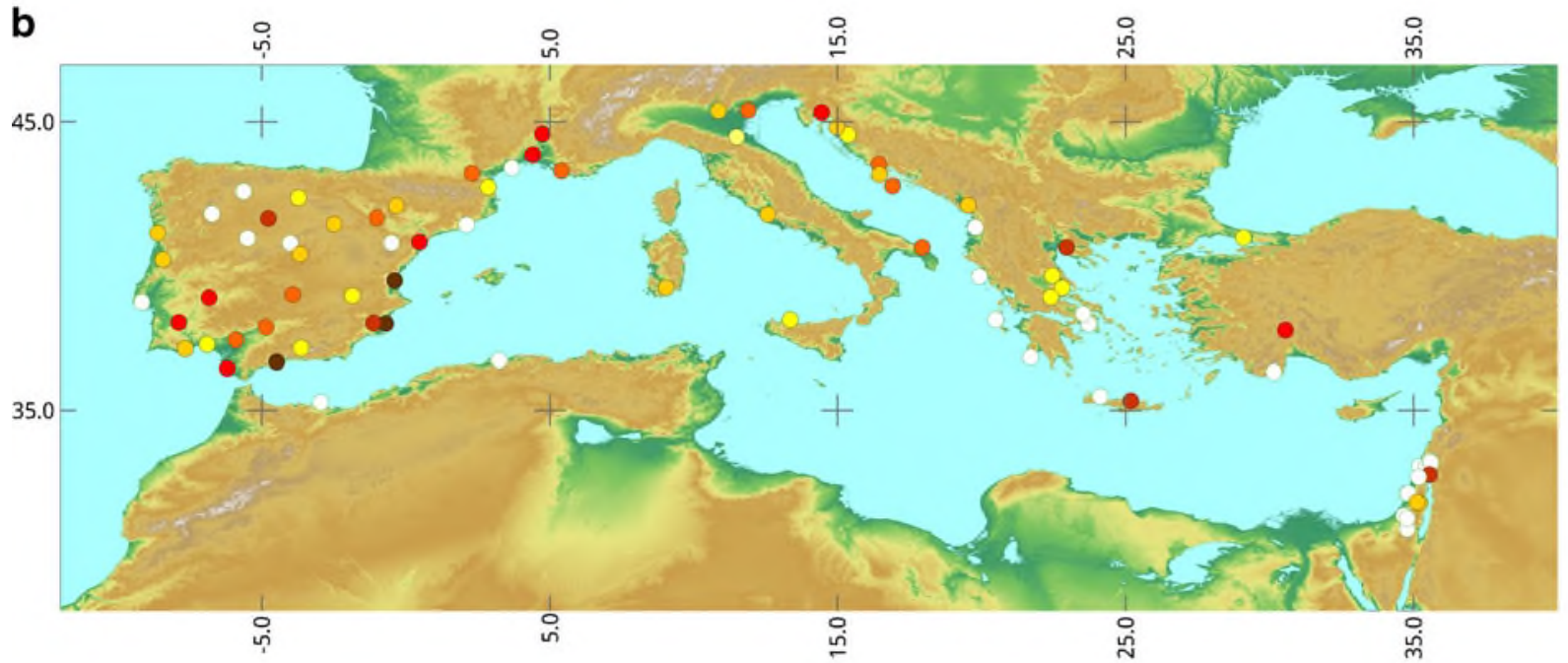

$-9999$

$0.0 \cdot 0.1$

$0.1-0.2$

$0.2 \cdot 0.3$

$0.3 \cdot 0.4$

$0.4 \cdot 0.5$

- $0.5-0.6$

- $0.6-0.7$

- $0.7-0.8$

- $0.8-0.9$

- $0.9-1.0$

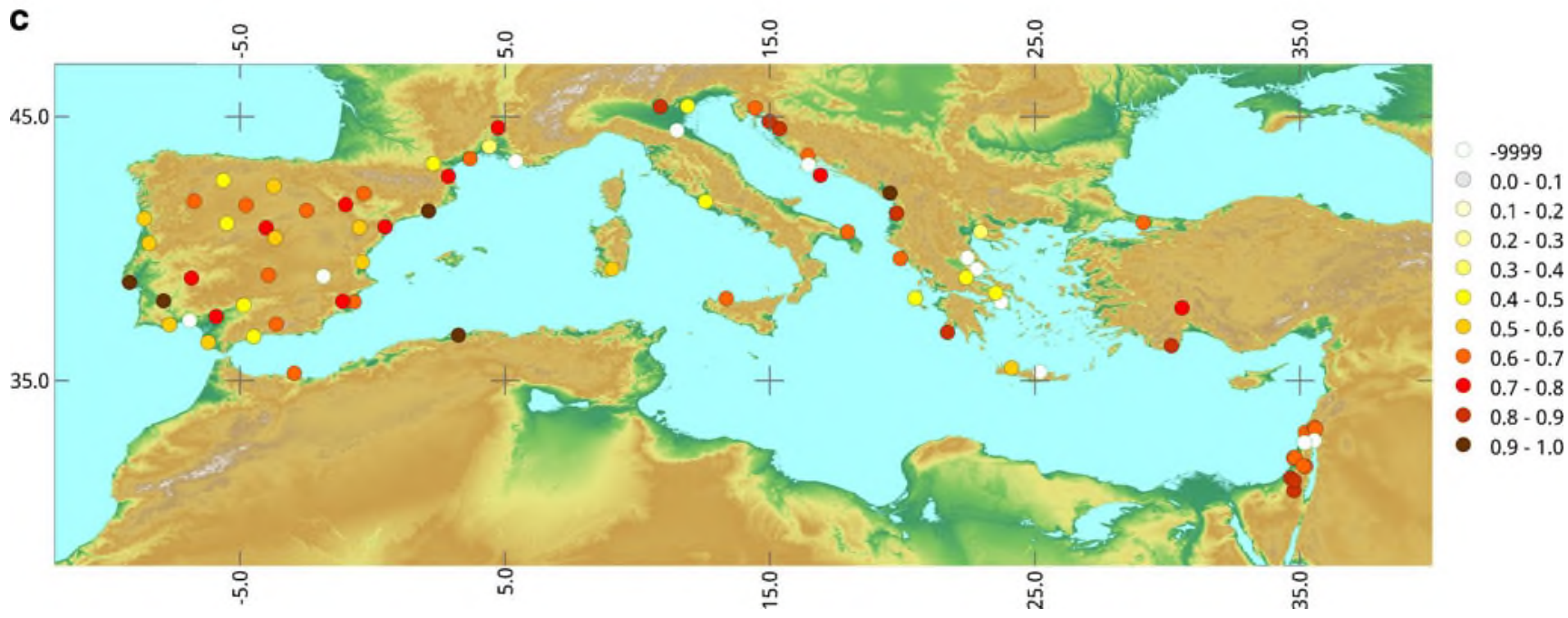

Fig. 2 Ratio of overlapping (ROO) for 30-year TMAX events in spring (a), summer (b) and autumn (c). Valid models are displayed with yellow and red circles and non-valid ones with white circles; see text for explanation 
over the period 1871-2008. Selecting three smaller predictor domains instead of one bigger "Mediterranean domain" tries to avoid the embedding of dispensable information (often corrupting model quality) for the three different Mediterranean subregions.

Downscaling future changes of Mediterranean precipitation and maximum temperature is applied to ECHAM5/MPI-OM coupled GCM data (Roeckner et al. 2003, 2006) generated for the IPCC AR 4 report. The study of Brand et al. Brand et al. (2011), in which a downscaling of daily temperatures in the Northwestern Iberian Peninsula via analogue method amongst others from ECHAM5/MPIOM control runs (amongst others) is applied, shows a good agreement between the cumulative distribution functions of observed and downscaled temperatures in the focused region. This leads to the conclusion that the distribution of weather types in ECHAM5/MPI-OM model output is reasonable compared to the observations ensuring meaningful projection results. Also, the publication of Pinto et al. (2007) highlights the quality of synoptic circulations reproduced by ECHAM5/MPI-OM over the Mediterranean area. Altogether, three control runs (CTRL) and three different runs for each of the SRES emission scenarios (SCEN) A1B and B1 (Nakicenovic and Swart 2000) are taken into account. Two time slices are compared: the period 19611990 (control runs) representing present conditions and the period 2070-2099 (scenario runs) incorporating potential future changes. In order to fit the ECHAM5/MPI-OM data to the reanalysis grid, the former has been projected by bicubic interpolation onto the $2^{\circ} \times 2^{\circ}$ grid.

\section{Methods}

The estimated future changes of maximum temperature and precipitation extremes are based on (1) downscaling of the daily precipitation (PRC) and TMAX values from the large-scale GCM circulation (by means of SLP) via analogue method and (2) a posteriori fitting of the generalized Pareto distributions to the resampled PRC and TMAX extreme values of the CTRL as well as the SCEN periods. The probabilities of extreme events are derived from generalized Pareto distribution (GPD) and expressed by means of return values. Finally, the shifts in future extremes (between CTRL and SCEN) are assessed via the changes of the 30-year return values. The procedure of estimating the return values as well as assessing the significance of return value's future changes is explained in Section 3.1. Previously to these analyses, a model validation procedure has been designed which is exposed in Section 3.2. The quality of statistical models is checked with a bootstrapping approach using calibration and validation periods from observational data (1871-2008). If the quality of models in observational periods is sufficient, models are assigned to GCM data. Otherwise, station time series in affected seasons are excluded from future downscaling processes.

\subsection{Downscaling approach}

The first step of the downscaling scheme consists of the application of the analogue method following Zorita and von Storch (1999):

For any daily ECHAM5-MSLP field of the periods 1961-1990 (CTRL) and 2070-2099 (SCEN), one analogue, being the most similar daily pattern out of NCEP V2 data spanning the period $1871-2008$, is identified via minimum Euclidean distance (ED)

$\operatorname{ED}\left(X_{1}, X_{2}\right)=\left[\sum_{i=1}^{m}\left(X_{1 i}-X_{2 i}\right)^{2}\right]^{1 / 2}$

where $X_{1}$ is a CTRL, a A1B or a B1 pattern; $X_{2}$ is a NCEP V2 pattern; and $m$ is the number of grid points.

Subsequently, new samples of PRC and TMAX values for each station are compiled by selecting those PRC and TMAX values which are associated with these most similar (i.e. analogue) MSLP patterns. This is done for both periods CTRL and SCEN.

In some cases where the station records do not span the whole NCEP V2 period, reduced periods for searching for analogues have to be used as documented in Table 1.

Because the length of the time series of any station record is the limiting factor for the period in which analogues are identified, the whole NCEP V2 period cannot always be used for this purpose (see Table 1 for time series lengths of the different stations).

Within this first step, the influence of a potential model bias (i.e. systematically different MSLP averages and variances) has to be considered. However, several authors report that ECHAM5/MPI-OM has a particular low bias in the Mediterranean area compared to other models (Pinto et al. 2007; Brand et al. 2011; Lorenzo et al. 2011). Furthermore, the statistical method itself counteracts the influence of biases. Thus, when searching most similar MSLP fields, it is not the absolute level of Euclidean distances that is relevant but only the relative similarity between different pairs of patterns which counteracts the influence of systematically higher/lower MSLP values in the model. Furthermore, using only the differences between the CTRL and the SCEN model runs and not the differences between model and observation (see the delta approach in Räisänen 2007) additionally counteracts the impact of the model bias. 
In the second step of the procedure, a GPD is fitted to the extremes of each of the new station time series for CTRL (1961-1990) and SCEN (2070-2099).

The probability $\operatorname{Pr}$ for values of $X$ equal $x>u$ is

$\operatorname{Pr}\{X>x \mid X>u\}=\left[1+\xi\left(\frac{x-u}{\sigma}\right)\right]^{-1 / \xi}$

with threshold $u$ (here the station-specific 85th to 95th percentiles) and $\xi$ as well as $\sigma$ being the GPD's shape and scale parameter and

$\operatorname{Pr}\{X>x\}=\zeta_{u}\left[1+\xi\left(\frac{x-u}{\sigma}\right)\right]^{-1 / \xi}$

with $\zeta_{u}=\operatorname{Pr}(X>u)$ (see Coles 2001).

In the present study, a GPD is obtained not only for one but also for a range of thresholds between the stationspecific 85th and 95th percentiles (see Paeth and Hense 2005). The GPD parameter is determined by the methods of L-moments (Hosking 1990; Kharin and Zwiers 2000). The Pareto model assumption as well as the quality of GPD fit is checked with the Kolmogorov-Smirnov goodness-of-fit test (see Kharin and Zwiers 2000). The estimated probabilities of extreme events are expressed in terms of $N$-year return values. The $N$-year return value is defined as the threshold that is exceeded once every $N$ years and estimated as depicted in Coles (2001) as

$z_{N}=u+\frac{\sigma}{\xi}\left[\left(N n_{y} \zeta_{u}\right)^{\xi}-1\right]$

for $\xi \neq 0$ with $n_{y}$ as the number of observations per year. In the present study, the 30-year return values are focused. Moreover, uncertainties of return value estimation are taken into account following Kharin and Zwiers (2000) and Paeth and Hense (2005). The authors identified small sample sizes-as they are usually the case in dealing with extremes-as one potential reason for uncertainties in the return value (RV) estimation. According to Paeth and Hense (2005), it is possible to consider the level of those uncertainties by assessing return values via a parametric bootstrap sampling. Hence, the GPD is primarily fitted to the PRC or TMAX extremes exceeding a station-specific threshold (i.e. the original PRC or TMAX extreme series, e.g. based on 90th percentile), and from the resulting GPD parameter, the cumulative distribution function is calculated. Afterwards, $n$ (i.e. the size of original extreme value series) random numbers $r$ between 0 and 1 are drawn, representing-in terms of the cumulative GPD distribution function-the probability that a realization of a random variable (here an extreme value) will occur below the corresponding value indicated by the GPD. In this way, $n$ randomly selected extremes are derived from the cumulative GPD of the original extreme value series. That process is repeated 100 times resulting in 100 artificially generated extreme series of size $n$. GPD then is fitted to those 100 extreme series. Afterwards, the 30 -year return value is obtained as the mean of those 100 different 30-year return values. As mentioned above, in the present study, GPD was obtained not only for one but also for totally 11 different thresholds (station-specific 85th and 95th percentiles). Thus, the just illustrated procedure is performed separately for each of the 11 thresholds leading to 11 different RV means. Afterwards, one singular return value is assessed as the mean of all the $11 \mathrm{RV}$ means. In this manner, RVs are calculated for PRC and TMAX of any Mediterranean station in each of the periods 1961-1990 and 2070-2099. The difference between 30-year return values of 2070-2099 and 1961-1990 shows the direction (increase or decrease) and strength of changes of 30-year extreme events in the future. It has to be referred that resampling techniques are accompanied with uncertainties when applying in the extreme framework (Dupuis and Field 1998; Qi 2008). In order to consider this at least partially, the here developed validation procedure (see Section 3.2) is based on determining the accordance between the return values derived from downscaled and those from observed time series.

The significance of future changes is determined according to Frei et al. (2006) by means of a non-parametric bootstrapping of confidence intervals for the relative change in return values. Therefore, 50 bootstrap samples were generated from the downscaled CTRL as well as SCEN time series of any weather station. The resulting $2 \times 50$ different time series consist of downscaled daily PRC and TMAX values of totally 30 randomly selected years from CTRL and SCEN periods, respectively. For any of those $2 \times 50$ time series, extremes are defined relative to various thresholds, generalized Pareto distributions are fitted and the 30-year return values are estimated as explained in Section 3.1 (separately for PRC and TMAX). The resulting 50 different 30-year RVs from each of CTRL and SCEN periods are afterwards resampled 1,000 times. Thus, 1,000 times one of the 50 SCEN and one of the 50 CTRL RVs is randomly chosen and the SCEN RV/CTRL RV ratio is calculated. From the resulting 1,000 different ratio values, the $90 \%$ confidence interval is derived. If the value of 1.0 , representing no change between CTRL and SCEN return values, lies outside this $90 \%$ confidence interval, the future change of $\mathrm{PRC}$ and/or TMAX extremes at the corresponding station is accounted as significant with $\alpha=0.1$. Results are displayed in Figs. 3 and 4 of Section 4.2.

\subsection{Model validation}

The uncertainties of the statistical GPD models have to be quantified in order to know about the quality of future 

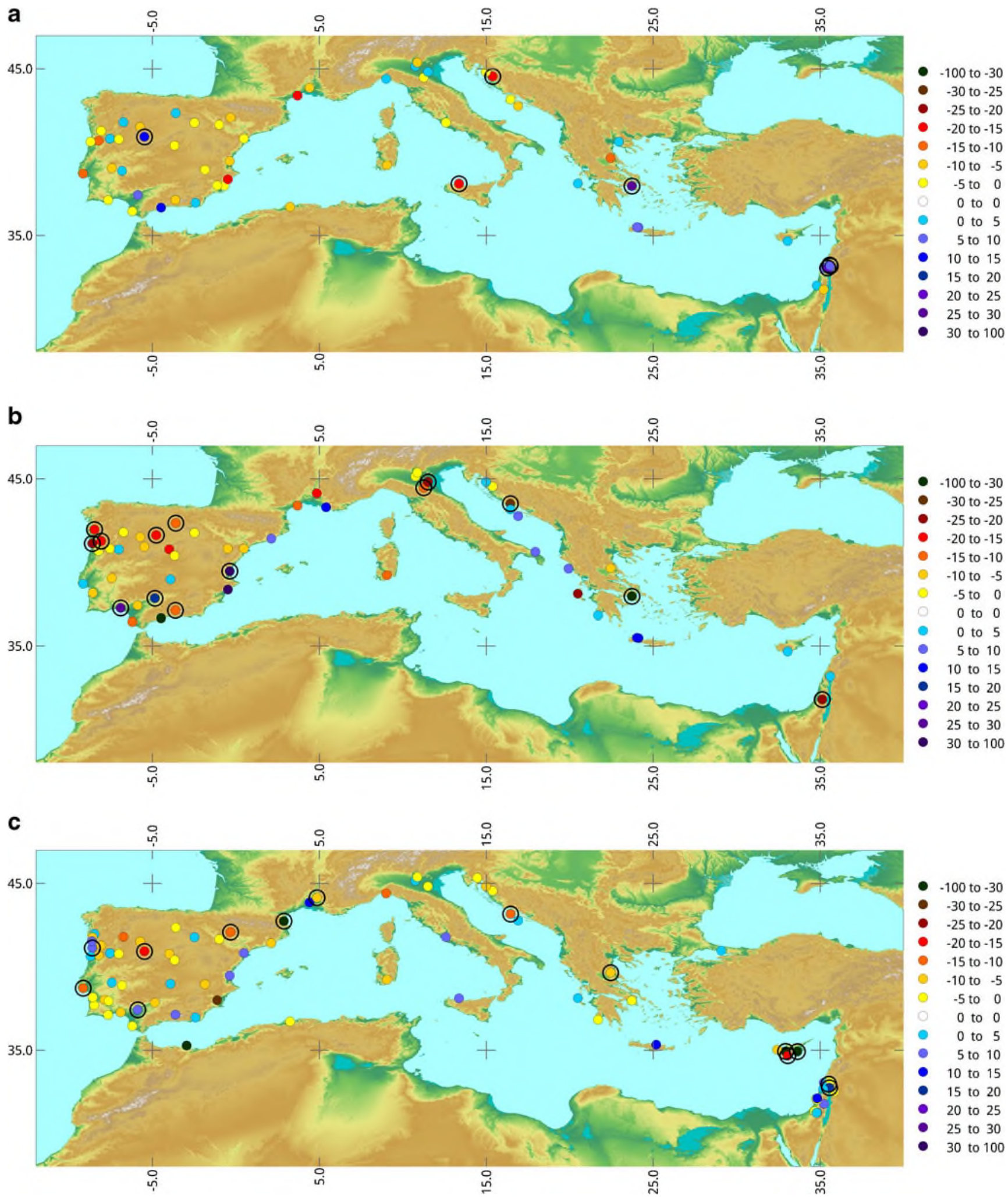

Fig. 3 Changes of 30-year return values of extreme precipitation for the future time period 2070-2099 of SRES B1 scenario in relation to the control run period 1961-1990 (in millimetre) for (a) spring, (b) autumn and (c) winter. Increasing (decreasing) 30-year return values in 2070-2099 are displayed in blue (yellow and red). Stations with significant changes $(\alpha=0.1$, see Section 3.1) are labelled with a black circle; see text for explanation 

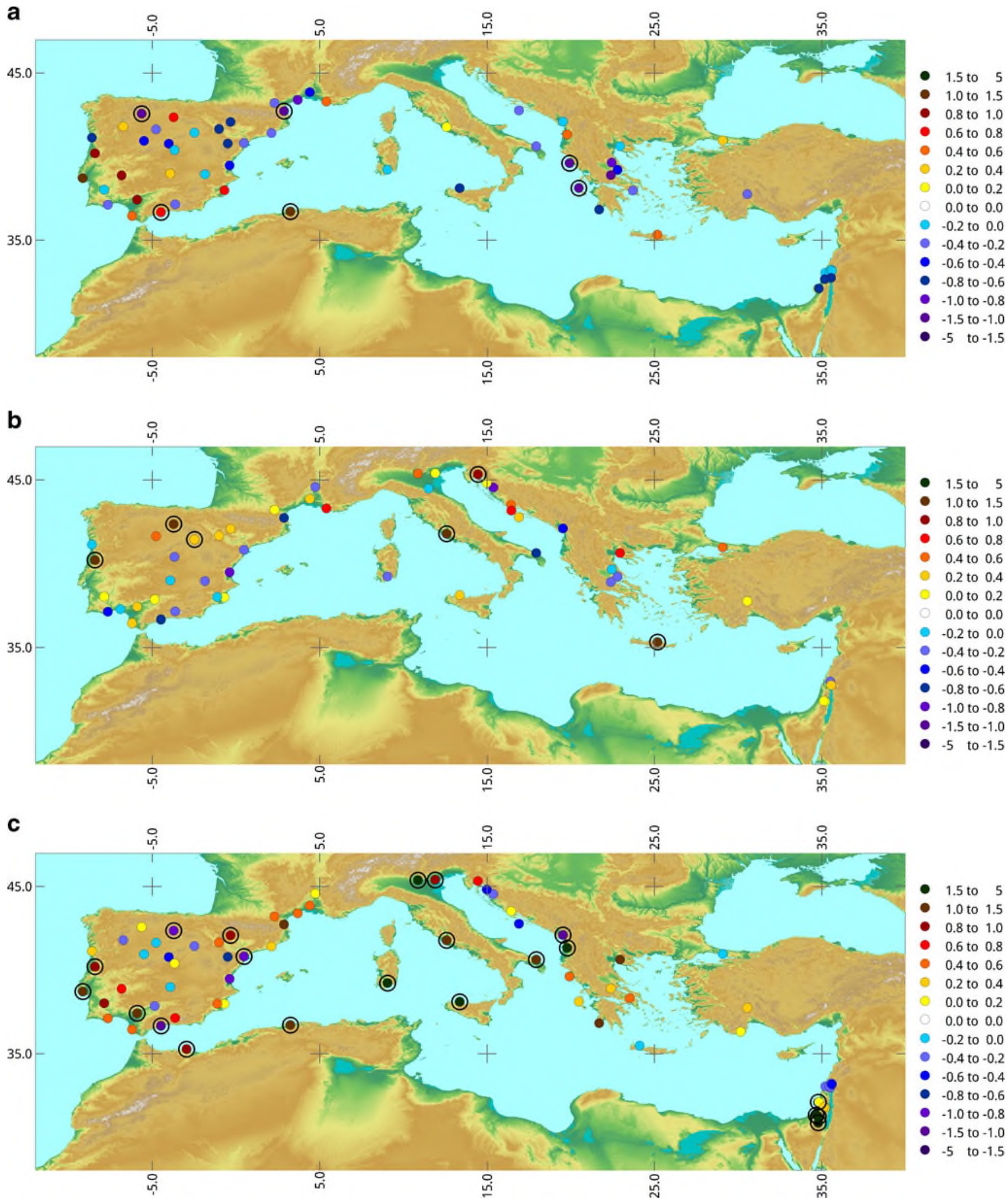

Fig. 4 Changes of 30-year return values of extreme maximum temperature for the future time period 2070-2099 of SRES B1 scenario in relation to the control run period 1961-1990 (in degrees Celsius) for (a) spring, (b) summer and (c) autumn. Decreasing (increasing) 30-year return values in 2070-2099 are displayed in blue (yellow and red). Stations with significant changes $(\alpha=0.1$, see Section 3.1) are labelled with a black circle; see text for explanation 
assessments. As mentioned before, uncertainties in RV estimation may generally result from dealing with small sample sizes which is always the case in addressing extremes. Those kinds of uncertainties can be considered, e.g. with the RV calculation by means of a parametric bootstrap sampling described in Section 3.1. But here, an additional question becomes apparent: how reliable are the future assessments of PRC and TMAX extremes? Or in other words, is the statistical downscaling of daily PRC and TMAX values via analogue method good enough even for representing the extreme events in a reliable manner? For addressing these questions and analysing the model quality related to the extremes expressed by 30-year return values, another bootstrapping of confidence intervals for return values according to Zwiers and Ross (1991) is applied. Therefore, at first, 30 individual seasons each with around 90 days (depending on the seasons DJF, MAM, JJA, SON) are randomly selected from a weather station's PRC or TMAX series with replacement. Such a random period is considered as one validation period. The resampling process is then repeated 100 times providing 100 different validation periods (out of one station series) each comprising 30 years $\times 90$ days. For any day of the 100 different validation periods, a real PRC and TMAX value at any weather station exists because the process of model validation is accomplished inside the observational data period (i.e. 1871-2008). Besides, the daily PRC and TMAX values of the 100 validation periods are also downscaled separately from the large-scale atmospheric circulation via analogue method. Afterwards, the whole process of determining 11 different percentile thresholds (85th to 95th percentiles), extracting extremes relative to these thresholds, fitting a GPD and estimating 30-year return values (as described in Section 3.1) is performed for both time series variants of the 100 validation periods, the 100 real existing (not downscaled) and the 100 downscaled time series. This results in 100 return values derived from observed (in the following observed RV ensemble) and 100 return values calculated from downscaled (in the following downscaled RV ensemble) time series of validation periods. The means of the modelled RV ensembles give the point estimates of return values; the associated confidence intervals are determined as the first and third quartiles (25th and 75th percentiles) of the observed ensemble of return values.

We also derive the first and third quartiles of the downscaled return value ensemble, because they allow to check the overlapping of the confidence intervals of both RV ensembles, the observed and downscaled ones, "in a traditional way". Normally, this method is applied for verifying a significant difference between the distributions of two ensembles accompanied by the rejection of the 0-hypothesis (Kharin and Zwiers 2000; Paeth and Hense 2005). Then, the values associated with the 5th and 95th percentiles of both ensembles are defined as lower and upper $90 \%$ confidence bounds. A difference between both ensemble's distributions is supposed to be statistically significant with $\alpha=0.1$ if their $90 \%$ confidence intervals do not overlap (e.g. Kharin and Zwiers 2000). In contrast to that and in our case, the aim is not to reject but to maintain the 0-hypothesis. Therefore and in order to avoid an error of the second kind (an erroneous maintaining of the 0 -hypothesis), the confidence bounds have to be narrowed. Hence, the 25th and 75th percentile values were taken as confidence interval limits which is a synonym for lowering of the significance level (e.g. to $50 \%$ when focusing the first and third quartile values). Thus, if both confidence intervals overlap, a significant difference cannot be postulated even with a very low significance level. Besides the above-mentioned first validation criterion, an acceptable model additionally has to reach an overlapping of the confidence intervals from the observation and the downscaling ensembles. In order to differentiate between acceptable, good and high quality models, we defined a simple but very useful metric called ratio of overlapping (ROO). It measures the ratio of overlapping between two confidence intervals in terms of a particular coefficient with values between 0 and 1 . If there is a perfect (no) agreement between modelled and observed return values, ROO is equal to $1(0)$. ROO is determined by

$\mathrm{ROO}=\frac{\mathrm{CR}}{\mathrm{TR}}$

with $\mathrm{CR}$ as the common range and TR as the total range of both confidence intervals where

$\mathrm{CR}=\mathrm{CI}_{\text {MINUL }}-\mathrm{CI}_{\text {MAXLL }}$,

with $\mathrm{CI}_{\text {MINUL }}$ as minimum upper and $\mathrm{CI}_{\text {MAXLL }}$ as maximum lower limit of both confidence intervals CI, and

$\mathrm{TR}=\mathrm{CI}_{\mathrm{MAXUL}}-\mathrm{CI}_{\mathrm{MINLL}}$,

with $\mathrm{CI}_{\text {MAXUL }}$ as maximum upper and $\mathrm{CI}_{\mathrm{MINLL}}$ as minimum lower limit of both intervals. Acceptable models are defined by ROO $>0$, good models by ROO $>0.5$ and high quality models by ROO $>0.75$. ROO values for all Mediterranean stations in the different seasons are displayed in Figs. 1 and 2 of Section 4.1. As mentioned before, those stations are excluded from further analyses, i.e. the future downscaling procedure, with ROO values equal to 0 (displayed as red and white symbols in Figs. 1 and 2). In contrast, if a model for PRC or TMAX extremes is acceptable (ROO > 0), daily PRC or TMAX values for the corresponding station and season are subsequently downscaled from ECHAM5/MPI-OM circulation for CTRL and SCEN periods. Subsequently, extreme events are derived and 30-year RVs are calculated as described in Section 3.1. Finally, the future RV shifts are determined and checked for their significance (as explained in Section 3.1). The results 
of both steps just mentioned are displayed in Figs. 3 and 4 of Section 4.2.

\subsection{Circulation analysis}

Beyond deriving future changes of climatic parameters by statistical assessments, it is useful to get an idea about the underlying physical and dynamical processes. Hence, the obtained future changes of precipitation and maximum temperature extremes are analysed with respect to connected changes of the corresponding atmospheric circulation. Therefore, the daily MSLP patterns in autumn (SON) of 1961-1990 and 2070-2099 associated with the extreme days at two selected stations, Porto in the Western and Be'er Sheva in the Eastern Mediterranean area, are classified by a non-hierarchical SANDRA cluster analysis (see Philipp et al. 2007)."Extreme days" in this case are defined more moderately as those days with PRC or TMAX values above the station-specific 85th percentiles. The relatively low percentile value is chosen because the GPD models are obtained for the station-specific ranges of thresholds starting at 85th percentile (see Section 3.1). For the sake of comparability of results, circulation analyses should have the same database as the extreme value models. Autumn season is focused because the regional PRC and TMAX differences between 1961-1990 and 2070-2099 in the two selected areas around Porto and Be'er Sheva are pronounced quite clearly (see Figs. 3b and 4c). For any of the two selected stations, nine circulation types related to extremes are derived from the pool of station-specific CTRL and SCEN extreme days. A number of nine circulation types is chosen following the classification catalogues of COST 733 (Harmonisation and Applications of Weather Type Classifications for European Regions), where most often 9, 18 or 27 types for seasonal as well as whole-year circulation classifications are preferred (Philipp et al. 2010). Centroids are calculated as composites of all individual MSLP patterns in one particular cluster (CL) resulting from the SANDRA classification. Analysing the frequency changes of these circulation types between CTRL and SCEN periods gives information about the changing character of circulation dynamics associated with the extremes. The results of these analyses with regard to modelled extremes are discussed in Section 5.

\section{Results}

\subsection{Quality of models}

GPD model quality for the return values of 30-year events is presented for extreme precipitation in spring, autumn and winter in Fig. 1 and for TMAX extremes in spring, summer and autumn in Fig. 2. Model quality is expressed by the ratio of overlapping (see Section 3.2) assigning high (low) quality models by dark (bright) colours in blue for PRC and red for TMAX extremes.

Model quality for extreme precipitation in spring (Fig. 1a) is heterogeneous. There is a good agreement between modelled and observed return values for most stations on the Iberian Peninsula and the Central Mediterranean area indicated by ROO values of $>0.6$. High quality models with ROO values of $>0.8$ are found for Northern Italy stations. In contrast to that, not only for most stations in the Eastern Mediterranean area but also for singular stations in Portugal and Central Iberia, no valid models could be set up. In autumn (Fig. 1b), a similar situation is obvious: for even more stations in Central Iberia (compared to spring) and for nearly all stations in the Central Mediterranean area (mainly at the Eastern Adriatic coast), model quality is sufficient. But at the same time, models are non-valid on the south-eastern coastline of the Iberian Peninsula and for the North African stations. In winter (Fig. 1c), a high model performance is evident for the majority of Mediterranean stations except of some locations in the Southern Central and in the Eastern Mediterranean areas.

This seasonally varying picture of model quality leads to the conclusions that in winter, precipitation extremes are linked best to large-scale circulation variability and the occurrence of extreme event-relevant patterns. However, in spring, the occurrence of specific circulation patterns is not the main trigger for precipitation extremes in some regions, e.g. in North Iberia. Rather, additional features (like, e.g. moisture flux, convection) not captured in the actual predictor field (MSLP) might play an important role for the development of extreme events. Besides, there are regions, like, e.g. Northern Italy - the region with the highest model quality in spring - where not only mean precipitation (Trigo et al. 2002) but also extreme precipitation seems to be linked very strongly to regional and large-scale cyclogenesis reflected by the mean sea level pressure field. In the "dry" Eastern Mediterranean region, another problem becomes apparent in spring and in autumn: since there are very few rainy days, the seasonal samples of extreme events can get too small to obtain a robust fit of the generalized Pareto distribution for these seasons - a further reason for getting non-valid models.

Model performance of TMAX extremes in transitional seasons is generally higher than that of PRC extremes. In spring (Fig. 2a), the highest ROO values of $>0.8$ are achieved by stations in the central and south-western parts of the Iberian Peninsula and in the Southeastern-Central Mediterranean regions (Balkans, Greece). In Northern Italy, at the Croatian coastline and in the southerly Eastern Mediterranean area, models are non-valid. In summer, model 
robustness is lower than that in autumn and spring (Fig. 2b): for several stations in Northern Iberia, Greece and the Eastern Mediterranean region, no robust models exist. Considering the Central Mediterranean area, there is an interesting north-south contrast between spring and summer: spring models are unsatisfactory for stations in Northern Italy and on the Croatian coastline, but of high quality on South Adriatic coastal sites and at Greece locations (see Fig. 2a). In summer, the situation is mirrored: model quality is good for stations in North Italy and the Northern Adriatic coast, whereas for Greece and South Adriatic coastal stations, model quality is insufficient. Model performance in autumn (Fig. 2c) is satisfying for nearly the whole Mediterranean station pool. Even in the southern parts of the Eastern Mediterranean areas, valid models could be set up. Hence, TMAX extremes are linked more strongly to largescale circulation patterns in autumn compared to spring. However, in spring, the strength of the reinforcing PersianArabian heat low, only weakly accentuated in MSLP fields, strongly drives the occurrence of TMAX extremes. While TMAX extremes in spring and summer are associated more strongly to local and regional circulation characteristics (e.g. windward/lee side exposure or local thermal low effects), a Mediterranean-wide robust link between temperature extremes and the large-scale mean sea level pressure variability exists in autumn. In summary, there is a broad confidence in the models for wintertime extreme precipitation as well as for extreme maximum temperatures in the autumn season.

4.2 Future changes of extreme precipitation and maximum temperatures

In the following, future changes of return values of 30-year events are discussed. Changes are derived as the differences between 2070-2099 (SCEN) and 1961-1990 (CTRL) return values. In general, the results for the A1B and B1 scenarios are comparable. Since spatial patterns of future changes often are more coherent in B1 results, only those ones are highlighted in this section. Future changes of extreme precipitation (in millimetre) are presented in Fig. 3 and of extreme maximum temperatures (in degrees Celsius) in Fig. 4. Only the results of valid models (see Figs. 1 and 2 in Section 4.1) are displayed.

Changes of extreme precipitation are spatially strongly varying. With respect to changes in spring (Fig. 3a), the differences between 2070-2099 and 1961-1990 return values are mostly negative. Therefore, the amounts of 30-year events in 2070-2099 are lower than those in 1961-1990 mainly in the Western (West and Northeast Iberia) and Central Mediterranean areas (South Italy,
Eastern Adriatic coast). In contrast, in the Eastern Mediterranean region (Greece, Israel) 30-year return values are increasing. Changes are mostly moderate and account for around 10-15 mm. Often, like, e.g. in Northwestern Spain, a station with stronger 30-year events in the future (bluecoloured in Fig. 3) directly lies besides a station with less extreme 30-year events (yellow/red-coloured in Fig. 3). This small-scale variation of changes is also described in Hertig et al. (2013), analysing seasonal extreme indices with GLMs based on gridded Mediterranean precipitation data. Obviously, changes of extreme precipitation events are influenced not only by large-scale circulation dynamics but also by local-scale factors like for example thermodynamic forcing. However, overall tendencies like those mentioned above become apparent. In autumn, a strong decrease in the intensity of extreme PRC events is obvious in Northern Spain and Northern Italy which reaches up to -20 to $-30 \mathrm{~mm}$. In contrast, in the Southern Central Mediterranean area (South Italy, Albanian and Croatian coastline), return values of 30-year events increase up to $15 \mathrm{~mm}$. For the Eastern Mediterranean region, it is hard to make clear statements due to the lack of stations with robust models. But according to increasing levels in Southern Greece, Crete and Cyprus, a rise of return values mainly in the north-eastern parts (Lebanon, Syria) seems to be due. Changes in wintertime extreme precipitation events behave similarly like those in spring. In the major parts of the Iberian Peninsula, 30-year events will decline by mostly around -5 to $-10 \mathrm{~mm}$. At the Northern Portugal coast and at the South- and Northeastern Mediterranean coastline of Iberia, 30-year events will increase in precipitation amounts. The same is true for Southern Italy and, above all, for the Southeastern Mediterranean area. However, in the Northeastern Mediterranean region and in Cyprus, a decrease of return values of up to $-30 \mathrm{~mm}$ is observed. Regarding the significance of future changes (see Section 3.1), depicted as black circles in Fig. 3, the increases of return values for 30-year events in the Northeastern Mediterranean region in spring and winter are significant at several stations with $\{\alpha=0.1\}$. For the remaining Mediterranean area, e.g. for Iberia, significant changes in the same seasons are only observed at a few stations. This is in general accordance with the findings of Frei et al. (2006) analysing future output of precipitation in different RCMs in terms of 5-year return values of seasonal 1-day precipitation maxima: the authors observe a decreasing tendency of return values in all examined seasons in Iberia, but at the same time, these changes are non-significant in autumn and winter and in nearly all the models. In contrast to that, here, the strong reduction of 30-year PRC return values in the Northwestern 
and Northern Central Mediterranean regions in autumn is significant in the present study (see Fig. 3b). This signal is further investigated and results are discussed in Section 5.

Concerning future changes of maximum temperature extremes, in spring (Fig. 4a), a basin-wide cooling of 30 -year events in the future is obvious (blue-coloured in Fig. 4). The difference of the seasonal (MAM) return values between 2070-2099 and 1961-1990 is negative at the majority of the Mediterranean stations, i.e. the 1961-1990 return values of 30-year TMAX events are roughly 0.5 to $1.5^{\circ} \mathrm{C}$ higher than the 2070-2099 return values. Maximum cooling of partially more than $-1.5{ }^{\circ} \mathrm{C}$ is reached in the Central Mediterranean (Balkans, Greece), the Spanish Pyrenees region and the southern parts of the Eastern Mediterranean area. In contrast, several stations in the south-west of the Iberian Peninsula, mainly in South Portugal, reveal a warming of 30 -year events of more than $1{ }^{\circ} \mathrm{C}$. In summer, the evolution of maximum temperature extremes in the future (see Fig. 4b) is spatially strongly varying and probably reflects the dominance of local-scale influences. In Northeastern Spain, in North Italy, at the Dinaric coastline and in the Eastern Mediterranean regions, TMAX return values rise in the order of around 0.4 to $0.8^{\circ} \mathrm{C}$. However, there are two main regions, nearly the whole coastline of the Iberian Peninsula as well as the Balkans and the north of Greece, where the return values of 30-year TMAX events in 2070-2099 are lower than those in 1961-1990. In contrast to the noticeable, basin-wide springtime cooling of TMAX extremes, an overall warming of 30-year maximum temperature events in autumn of 2070-2099 is indicated. The warming of TMAX extremes is most pronounced at stations in South Portugal, Italy and in the Southeastern Mediterranean areas, reaching warming rates of more than $1.5^{\circ} \mathrm{C}$. Moderately increasing TMAX extremes occur at Balkan's and Greece's weather stations. On the other hand, for the majority of Iberian locations, e.g. in central parts and at the Northeastern Mediterranean coastal region, a decline in 30year TMAX return values in the order of -0.4 to $-0.8^{\circ} \mathrm{C}$ is indicated. Concerning the significance of changes, depicted as black circles in Fig. 4, the warming of 30-year TMAX extremes in the Southwestern, Central and Southeastern Mediterranean areas in autumn is significant (with $\alpha=0.1$ ) at nearly all the stations (see Fig. 4b). For the Southeastern Mediterranean region, this signal is further examined and discussed in Section 5. Furthermore, the cooling of TMAX extremes in the Northwestern and Southern Central Mediterranean in spring as well as the increasing return values of 30-year TMAX extremes in North Iberia and the Central Mediterranean area in summer is statistically significant (with $\alpha=0.1$ ) at some stations.

\section{Discussion}

The most important future changes of extreme precipitation and maximum temperature in the Mediterranean area resulting from the study can be summarized as follows:

- A moderate decrease (increase) of return values for 30year PRC extremes in the majority of the Iberian Peninsula and the Adriatic coastline (Eastern Mediterranean area) accompanied by a nearly basin-wide cooling of TMAX extremes in spring

- Cooler (warmer) maximum temperature extremes at nearly all Iberian coastal sites (North Iberia) in summer

- A strong reduction (increase) of PRC return values in Northwest Iberia and in the vicinity of Italy (South Iberia) and a simultaneously distinct warming (cooling) of TMAX extremes in Southwestern Iberia (Central and Northeast Spain) and in the Central and Southeastern Mediterranean regions in autumn

- Reduced (increased) precipitation return values in the Central Iberian Peninsula and the north of Italy (Southeastern Iberia and Eastern Mediterranean) in winter

Generally, it has to be mentioned that the highlighted alterations in Mediterranean PRC and TMAX extremes are attributed to future changes of circulation dynamics described by mean sea level variations. It is difficult to differentiate to what extent background signals like the global warming, e.g. via higher air temperatures and moisture contents, larger pressure gradients and varying occurrences in distinct MSLP patterns, contribute to future shifts of the atmospheric circulation. This means, in the opposite way, that the here captured future developments probably are only a fraction of the whole picture of change.

Nevertheless, in focusing circulation mechanisms as potential reasons for the above-mentioned future developments, we may conclude the following: in the Western/Central Mediterranean area, spring conditions are generally drier in terms of both PRC extremes assessed in this study as well as precipitation totals (e.g. Hertig et al. 2013). These decreases are attributed to the widening of the descending branches of the Hadley circulation in the future (Lu et al. 2007). Thus, the frontal systems of Atlantic cyclones entering the Western/Central Mediterranean region and/or regional Mediterranean cyclogenesis are weakening, and therefore, deep frontal convection potentially causing PRC extremes is reduced. The prospective cooling of TMAX extremes in spring might be a result of reduced cyclonic influence as well: a decline in spring depressions, like, e.g. the Sharav or Genoa lows, results in a reduced 
advection of hot Sahara air masses typically related to the passage of these cyclone's warm sectors and is often the reason for extremely high temperatures in the Western/Central Mediterranean region.

Less frequently, a cool and dry spring in the Western Mediterranean can also result from the predominance of northerly advection due to blocking situations over the North Atlantic. While these situations may cause local precipitation, e.g. at the northern coast of Iberia, most of the Western Mediterranean and the Iberian Peninsula remains dry.

Maximum temperature extremes will be less severe for most of the Iberian coastal and southern sites in summer, while in the northern central region of Iberia, extreme temperatures show further warming. This spatial pattern, which is in principal identical to the results of the PRUDENCE (Prediction of Regional Scenarios and Uncertainties for Defining European Climate Change Risks and Effects) project (Räisänen et al. 2004, Fig. 10), may be explained by a strengthening of the thermal low in the north and interior of Iberia which will lead to strengthened coastal breezes with a cooling influence near the coast (Castro et al. 2005). Moreover, intensified evaporation rates over the sea together with enhanced local breezes might lead to increased coastal cloudiness damping the regional insolation and lowering maximum temperature extremes in the future. Additionally, increases in TMAX extremes in Northern Iberia may also be induced dynamically by anticyclonic ridges with underlying north-eastern circulation (Fernández-Montes et al. 2013), which will become more frequent according to B1-ECHAM5 scenarios, together with a decreased frequency of northerly and westerly circulation in the summer season (Lorenzo et al. 2011).

In winter, reduced precipitation extremes in the Western and Central Mediterranean areas may be the consequence of an increase in frequency of positive North Atlantic Oscillation (NAO) phases in the future as indicated by several GCMs (Coppola et al. 2005). Therefore, pressure configurations with southward displaced Atlantic lows being conducive to intensified precipitation in the Western
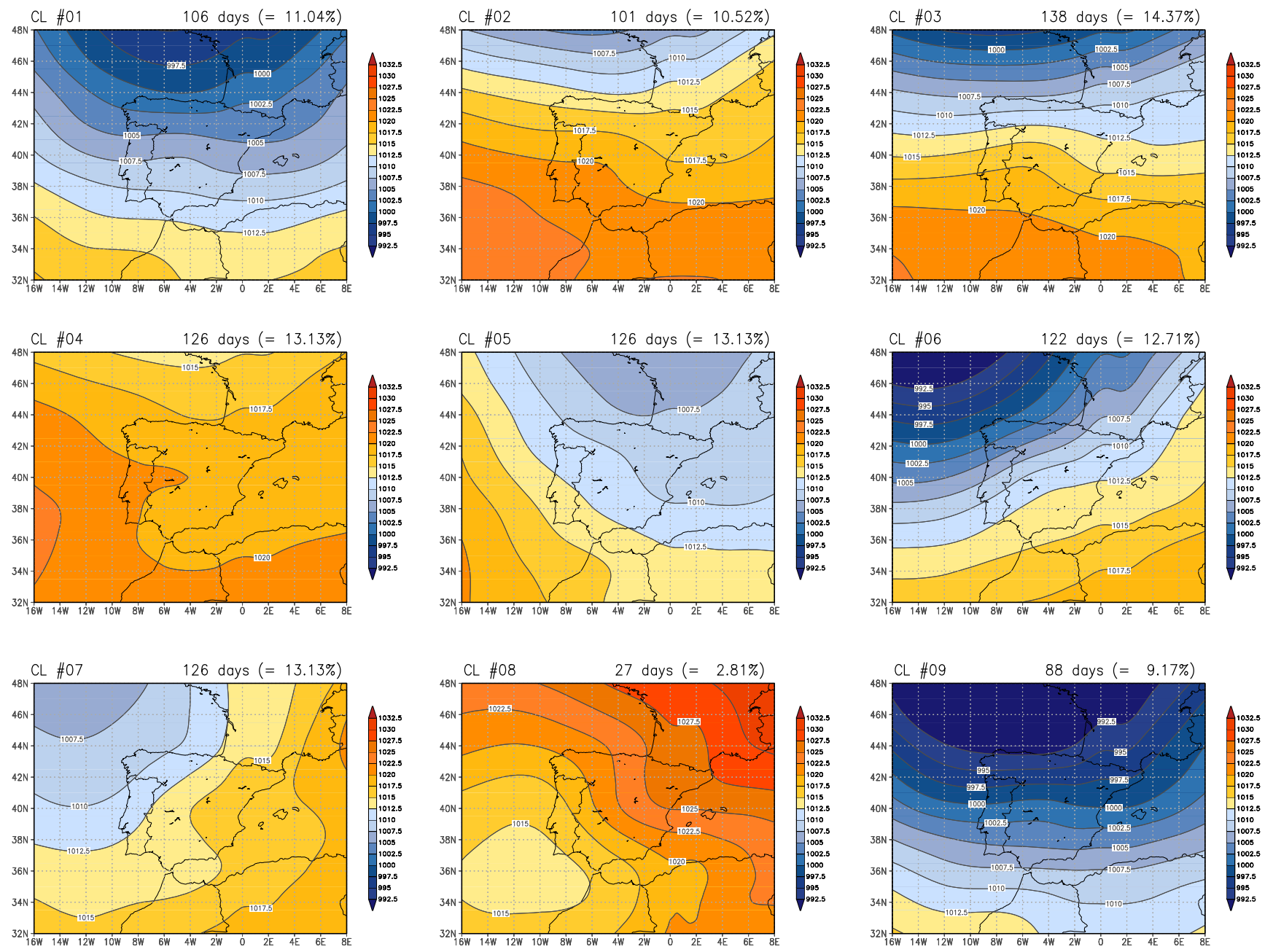

Fig. 5 MSLP centroids of nine circulation types related to precipitation extremes in Porto both in 1961-1990 (CTRL) and in 2070-2099 (SCEN) 
Mediterranean area are reduced, and this may be the reason for less severe precipitation extremes.

Additionally, the strong reduction of PRC return values in Northwest Iberia and the clear warming signal of maximum temperature extremes in the Southeastern Mediterranean region in autumn are analysed in terms of potential changes of the underlying circulation dynamics. For that purpose, two representative stations, Porto $\left(41.13^{\circ} \mathrm{N}, 8.60^{\circ} \mathrm{W}\right)$ and Be'er Sheva $\left(31.23^{\circ} \mathrm{N}, 34.78^{\circ} \mathrm{E}\right)$, are selected. The daily MSLP patterns associated with extreme events (beyond the 85th percentile in this case, see Section 3.3) in 1961-1990 and 2070-2099 are classified together (separately for any of the two stations, see Section 3.3). The centroids of the resulting nine clusters represent the station-specific circulation types linked to precipitation or TMAX extremes in autumn. They are displayed in Fig. 5 for heavy precipitation in Porto and in Fig. 6 for maximum temperature extremes in Be'er Sheva.

Precipitation extremes in Porto in autumn are frequently associated with Atlantic frontal systems passing Northern Spain and/or the Bay of Biscay. These are represented by different positions along typical cyclone tracks over the region: Thus, CLs 6 and 7 show a westward position of the low-pressure core, causing the advection of moist and warm air masses just before the cold front. When the low moves further eastward to the Gulf of Biscay (CLs 1, 2, 3, 4 and 9), a predominantly westerly flow component is associated with cold fronts crossing the Iberian Peninsula-the main trigger of heavy precipitation events. More rarely, low-pressure systems moving towards the Street of Gibraltar (CL 8) evoke heavy precipitation at Porto and the surrounding regions. All in all, this supports the assumption that the North Atlantic MSLP field and the associated dynamical flow components are the main drivers for the occurrence of PRC extremes in the north of Iberia (as it is in winter).

Regarding the TMAX extremes-connected MSLP fields above the Eastern Mediterranean area, Fig. 6 most often reveals low-pressure configurations with MSLP minima above Southeastern Turkey and Syria (CLs 1, 3, 4 and 6). The resulting southerly flow components advect hot and dry air masses from the Northern African desert regions to the Eastern Mediterranean and thus causing maximum temperature extremes in this area. The same is true for the weak regional low-pressure patterns (CLs 2, 7, 8 and 9) which
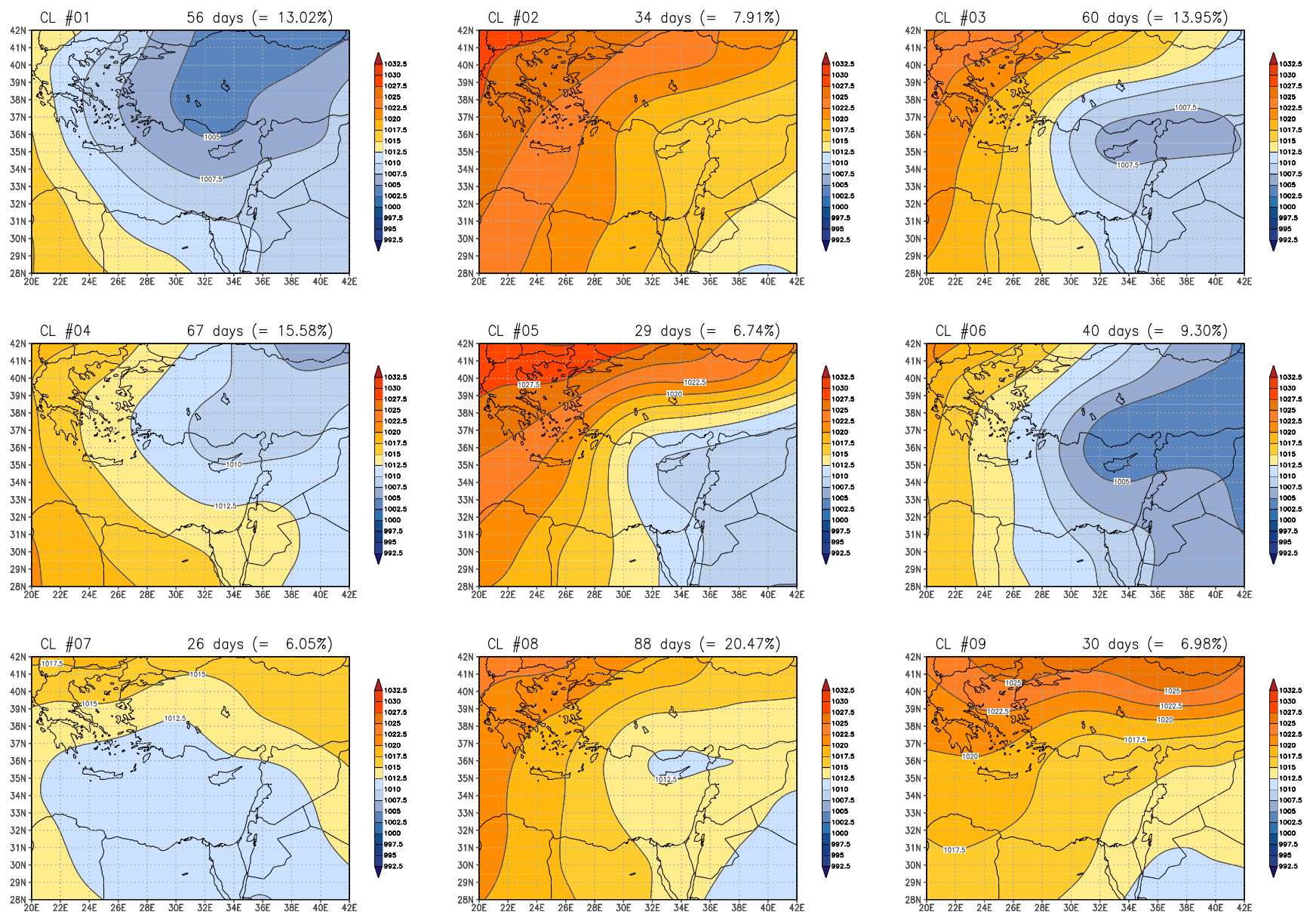

Fig. 6 MSLP centroids of nine circulation types related to TMAX extremes in Be'er Sheva both in 1961-1990 (CTRL) and in 2070-2099 (SCEN) 
are heat lows partly superimposed by Sharav lows or northward extended Red Sea Troughs (CLs 7-9). Additionally, these pressure patterns are accompanied by strong insolation rates-a further reason for the high temperatures at Be'er Sheva and Southeastern Mediterranean.

A comparison of the occurrence of any of the nine circulation types related to PRC or TMAX extremes between the periods 1961-1990 and 2070-2099 provides insight into changes of circulation dynamics relevant for climate extremes in the corresponding regions. Since frequencies in Fig. 7 are displayed as percentages of the total number of extremes during the CTRL and SCEN periods, it is possible to compare them directly, independently from the changes in absolute numbers of extremes events.

Distinct shifts in circulation-type frequencies between 1961-1990 and 2070-2099 for precipitation extremes in Porto are obvious (Fig. 7a). Most considerably is the decrease of frequencies of CLs 1 and 9 (low-pressure systems above the Bay of Biscay), whereas CL 4 (weak Azores high) and CL 5 (cyclone above Southwest France) clearly increase. Frequency changes of circulation types for TMAX extremes are somewhat less pronounced (Fig. 7b): mainly for one cluster, CL 3, representing a low-pressure pattern above Southeastern Turkey, a clear decline between CTRL and SCEN periods is manifesting. Besides, CL 1, depicting a cyclone above Central Turkey, and CLs 2 and 9, representing weak Persian Arabian heat lows, show some increasing frequencies from 1961-1990 to 2070-2099.

a

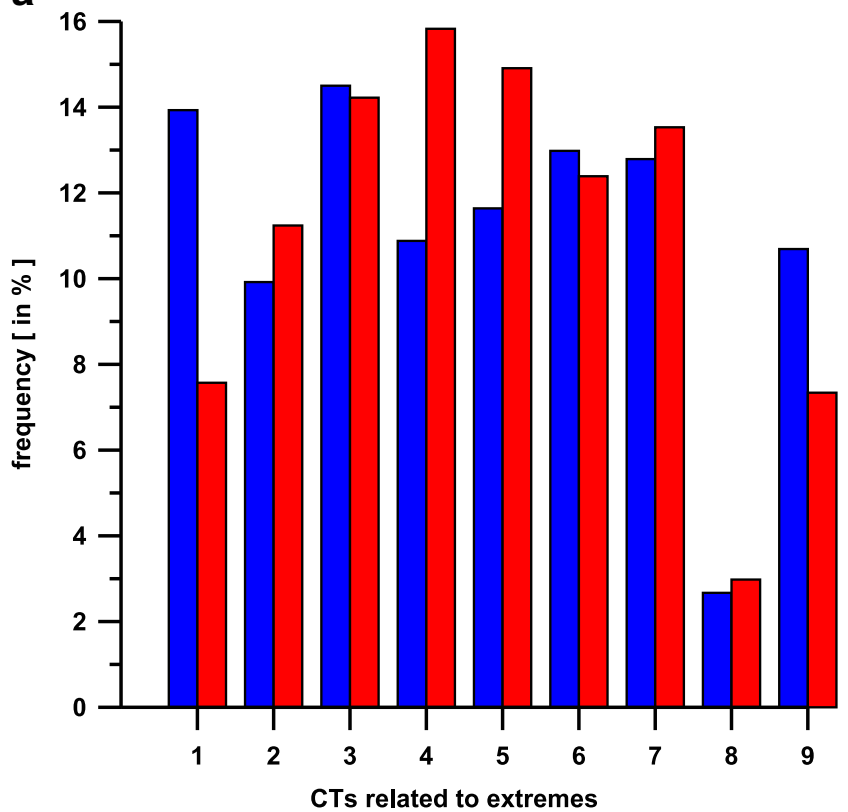

The relationship between the frequency changes of circulation types related to extremes and changes in autumn extremes in Porto and Be'er Sheva between CTRL and SCEN periods can be described as follows: the reduced values of 30-year return levels of PRC extremes in Northern Spain in autumn of 2070-2099 (see Section 4.2) may result from a reduced occurrence of southward displaced Atlantic frontal systems with strong low-pressure centres above the Northern Peninsula, as indicated by a decline of CLs 1 and 9 in 2070-2099 compared to 1961-1990 (see Fig. 7a). Also, patterns with large-pressure gradients above North Iberia (CLs 3 and 6) associated with strong frontal convective activity will occur less frequently, as shown, e.g. by the reduced frequencies of CLs 3 and 6 in 2070-2099 relative to 1961-1990. At the same time, patterns with ambiguous pressure configurations occur more frequently in 2070-2099 compared to 19611990: for example, CL 4, representing a weak Azores high permitting stronger heat-low-induced convection, and CL 5, associated with a cyclone above Southwest France and a relatively weak pressure gradient above Northern Spain. In summary, the results suggest a reduction of precipitation extremes connected to intense North Atlantic/Bay of Biscay cyclones. Furthermore, pressure configurations, depicting the trigger for extremes less clearly, become more important. They may include a more complex interaction with additional factors, like, e.g. atmospheric or soil moisture contents, leading to the development of extremes. At

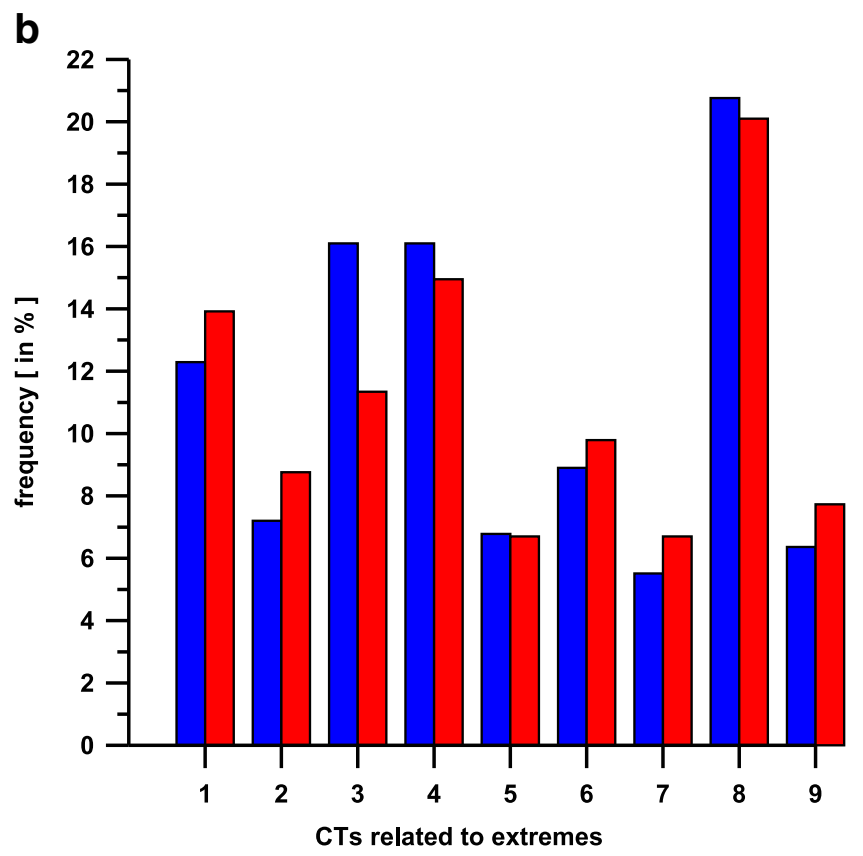

Fig. 7 Frequencies of nine circulation types (CTs) related to PRC extremes in Porto (a) and to TMAX extremes in Be'er Sheva (b) for 19611990 (blue bars) and for 2070-2099 (red bars). Frequencies are displayed as percentages of the total number of extremes during 1961-1990 and 2070-2099 
the same time, the dynamically induced strong convection, as given for extremes connected to deep Atlantic cyclones, is weaker and might result in "more moderate" precipitation extremes as depicted by the decline of 30-year PRC return values in Northwest Iberia.

Regarding TMAX extremes in the Eastern Mediterranean area (Be'er Sheva), increased return levels of 30-year events in 2070-2099 indicate a tendency towards hotter extreme temperature conditions there. In terms of the associated changes in circulation dynamics, we may conclude that CL 3, depicting a low-pressure pattern similar to the socalled "Cyprus low" (Saaroni et al. 2009), prevails less frequently. In contrast, a low above Central (CL 1) and Southwest Turkey (CL 6) as well as patterns with only weak low-pressure above the region (weakening of the PersianArabian heat low) and without distinct pressure gradients (CLs 2, 8 and 9) occur more frequently. Therefore, patterns characterized by the absence of cloudiness and high insolation rates become an important factor for TMAX extremes. But also patterns inducing southerly hot and dry air flow above the region increase in frequency (CLs 1 and 6). Two main factors for maximum temperature extremes might interact: patterns with thermal low conditions dominate the Southeastern Mediterranean area in autumn (SCEN), while a displacing of mid-latitude trough systems additionally provoke dynamical conditions for TMAX extremes.

Altogether, the results of circulation studies provide meaningful explanations for future changes of Western Mediterranean precipitation extremes. For TMAX extreme events in the Eastern Mediterranean area, results are not that much clear-cut but nevertheless provide valuable information about changing conditions for climate extremes in the future.

\section{Conclusions}

In the present study, precipitation and maximum temperature extremes in the Mediterranean area under SRES B1 conditions are assessed by the combined application of synoptic downscaling techniques and extreme value statistics. Several adaptations are necessary for achieving qualified results, like, e.g. the elaboration of a validation procedure which is specified for singular stations and deals with the quantification of uncertainties via bias-corrected bootstrapping. In this context, decision criteria for model quality have been designed, amongst others, on the basis of a new and simple measure (ROO) for the overlapping of bootstrapping confidence intervals. Model quality is best for extreme PRC in winter and TMAX extremes in autumn; it is limited for summer and partially for spring. Thus, further investigations addressing the enhancements of synoptic downscaling methods with regard to extremes are desirable. Concerning future changes of PRC and TMAX extremes in the Mediterranean area, the essential findings are (1) a nearly basin-wide cooling of TMAX extremes in spring, (2) a strong reduction of PRC 30year return levels in Northwest Iberia and the Northern Central Mediterranean area as well as a simultaneously distinct warming of TMAX extremes in Southwestern Iberia and Central and Southeastern Mediterranean in autumn and (3) reduced (increased) precipitation extremes in Central Iberian Peninsula and the north of Italy (Southeastern Iberia and the Eastern Mediterranean region) in winter. The most pronounced signal of change is detected for PRC extremes in Northwestern Iberia and TMAX extremes in the Southwestern, Central and Eastern Mediterranean regions in autumn. These signals are further analysed with regard to future variations of the associated circulation using circulation classifications. This compensates for a disadvantage of the analogue method, the deficient insight into circulation characteristics connected with a particular model variable. Frequency changes between 1961-1990 and 2070-2099 of resulting circulation types related to extremes in precipitation reveal a reduction of mainly one kind of relevant patterns, deep North Atlantic cyclones. This result fits with the discussion of a strengthening NAO in a changing climate and the coupled reduced influence of North Atlantic lows on the Western/Central Mediterranean region. Future work will address the combined usage of circulation classifications and transfer functions suitable for extreme-event assessments (e.g. generalized linear models) and extreme value statistics, to improve the remaining constraints of model results for summer and to gain a systematic understanding of the underlying circulation dynamics associated with the future changes of climate extremes.

Acknowledgments We acknowledge the DFG (German Research Foundation) for the financial support of KLIWEX-MED project.

\section{References}

Beguería S, Angulo-Martínez M, Vicente-Serrano S, López-Moreno J, El-Kenawy A (2011) Assessing trends in extreme precipitation events intensity and magnitude using non-stationary peaks-overthreshold analysis: a case study in Northeast Spain from 1930 to 2006. Nat Hazards Earth Syst Sci 31:2102-2114

Beniston M, Stephenson DB, Christensen O, Ferro C, Frei C, Goyette S, Halsneas K, Holt T, Jylhä K, Koffi B, Palutikof J, Schöll R, Semmler T, Woth K (2007) Future extreme events in European climate: an exploration of regional climate model projections. Clim Change 81:71-95

Brand S, Taboada JJ, Cofiño AS, Sauter T, Schneider C (2011) Statistical downscaling of daily temperatures in the NW Iberian Peninsula from global climate models: validation and future scenarios. Clim Res 48:163-176 
Castro J, Martin-Vide J, Alonso S (2005) Current and future climate in Spain. In: Assessment report on climate change and its impacts in Spain. Ministry of Environment, Spain

Cattiaux J, Vautard R, Yiou P (2010) North-Atlantic SST amplified recent wintertime European land temperature extremes and trends. Clim Dyn 36:2113-2128

Coles S (2001) An introduction to statistical modeling of extreme values. Springer, London

Compo GP, Whitaker JS, Sardeshmukh PD, Matsui N, Allan RJ, Yin X, Gleason BE, Vose RS, Rutledge G, Bessemoulin P, Brönnimann S, Brunet M, Crouthamel RI, Grant AN, Groisman PY, Jones PD, Kruk M, Kruger AC, Marshall GJ, Maugeri M, Mok HY, Nordli O, Ross TF, Trigo RM, Wang XL, Woodruff SD, Worley SJ (2011) The twentieth century reanalysis project. Quarterly J Roy Meteorol Soc 137:1-28. doi:10.1002/qj.776

Coppola E, Kucharski F, Giogi F, Molteni F (2005) Bimodality of the North Atlantic Oscillation in simulations with greenhouse gas forcing. Geophys Res Lett 32:L23709. doi:10.1029/2005GL024080

Dupuis DJ, Field CA (1998) A comparison of confidence intervals for generalized extreme-value distributions. J Stat Comput Simul 61:342-360

Fernández-Montes S, Rodrigo FS (2011) Trends in seasonal indices of daily temperature extremes in the Iberian Peninsula, 1929-2005. Int J Climatol 32:2320-2332. doi:10.1002/joc.3399

Fernández-Montes S, Seubert S, Rodrigo FS, Hertig E (2012) Wintertime circulation types over the Iberian Peninsula: long-term variability and relationships with weather extremes. Clim Res 53:205-227

Fernández-Montes S, Rodrigo FS, Seubert S, Sousa PM (2013) Spring and summer extreme temperatures in Iberia during last century in relation to circulation types. Atmos Res 127:154-177

Fisher R, Tippett L (1928) Limiting forms of the frequency distribution of the largest or smallest member of a sample. Proc Camb Philos Soc 24:180-190

Frei C, Schöll R, Fukutome S, Schmidli J, Vidale P (2006) Future change of precipitation extremes in Europe: intercomparison of scenarios from regional climate models. J of Geophys Res. doi: $10.1029 / 2005$ JD05965

Goubanova K, Li L (2007) Extremes in temperature and precipitation around the mediterranean basin in an ensemble of future climate scenario simulations. Glob Planet Change 57:27-42

Hertig E, Seubert S, Jacobeit J (2010) Temperature extremes in the Mediterranean area: trends in the past and assessments for the future. Nat Hazards Earth Syst Sci 10:2039-2050

Hertig E, Seubert S, Paxian A, Vogt G, Paeth H, Jacobeit J (2013) Statistical modeling of extreme precipitation indices for the Mediterranean area under future climate change. Theor Appl Climatol. doi:10.1002/joc. 3751

Hosking J (1990) L-moments: analysis and estimation of distributions using linear combinations of order statistics. J R Statist Soc B52:105-124

Katz R (1999) Extreme value theory for precipitation: sensitivity analysis for climate change. Adv Water Resour 23:133-139

Katz R, Parlange M, Naveau P (2002) Statistics of extremes in hydrology. Adv Water Resour 25:1287-1304

Kharin V, Zwiers J (2000) Changes in extremes in an ensemble of transient climate simulations with a coupled atmosphere-ocean GCM. J Climate 13:3760-3788

Kioutsioukis I, Melas D, Zerefos C (2010) Statistical assessment of changes in climate extremes over Greece. Int Journal of Climatol 30:1723-1737

Klein Tank AMG, Wijngaard JB, Können GP, Böhm R, Demarée G, Gocheva A, Mileta M, Pashiardis S, Hejkrlik L, Kern-Hansen C, Heino R, Bessemoulin P, Müller-Westermeier G, Tzanakou M,
Szalai S, Plásdóttir T, Fitzgerard D, Rubin S, Capaldo M, Maugeri M, Leitass A, Bukantis A, Aberfeld R, Van-Engelen AFV, Forland E, Mietus M, Coelho F, Mares C, Razuvaev V, Nieplova E, Cegnar T, López JA, Dahlström B, Moberg A, Kirchhofer W, Ceylan A, Pachaliuk O, Alexander LV, Petrovic P (2002) Daily dataset of the 20th-century surface air temperature and precipitation series for the European climate assessment. Int J Climatol 22:1441-1453

Kunstmann AHH, Rimmer A (2006) Physically based distributed hydrological modelling of the upper Jordan catchment and investigation of effective model equations. Adv Geosciences 9:123130

Lorenzo MN, Ramos AM, Taboada JJ, Gimeno L (2011) Changes in present and future circulation types frequency in Northwest Iberian Peninsula. PLoSONE 6(1):e16201. doi:10.1371/journal. pone. 0016201

Lu J, Vecchi G, Reichler T (2007) Expansion of the Hadley cell under global warming. Geophys Res Lett 32:L06805. doi:10.01029/ 02006GL028443

Mares C, Mares I, Stanciu A (2009) Extreme value analysis in the Danube lower basin discharge time series in the twentieth century. Theor Appl Climatol 95:223-233

Moberg A, Jones PD, Lister D, Walther A, Brunet M, Jacobeit J, Alexander L, Della-Marta P, Luterbacher J, Yiou P, Chen D, Tank AK, Saladié O, Sigró J, Aguilar E, Alexandersson H, Almarza C, Auer I, Barriendos M, Begert M, Bergström H, Bhöm R, Butler CJ, Caesar J, Drebs A, Founda D, Gerstengarbe FW, Micela G, Maugeri M, Österle H, Pandzic K, Petrakis M, Srnec L, Tolasz R, Tuomenvirta H, Werner P, Linderholm H, Philipp A, Wanner H, Xoplaki E (2006) Indices for daily temperature and precipitation extremes in Europe analysed for the period 1901-2000. J Geophy Res 111:D22106. doi:10.1029/2006JD0071031-55

Nakicenovic N, Swart R (2000) Emissions scenarios. Cambridge University Press, Cambridge

Naveau P, Nogaj M, Ammann C, Yiou P, Cooley D, Jomelli V (2005) Statistical analysis of climate extremes. Comptes rendus Geosciences de l'Academie des Sciences 337:1013-1022

Nikulin G, Kjellström E, Hansson U, Strandberg G, Ullerstig A (2011) Evaluation and future projections of temperature, precipitation and wind extremes over Europe in an ensemble of regional climate simulations. Tellus 63:41-55

Paeth H, Hense A (2005) Mean versus extreme climate in the Mediterranean region and its sensitivity to future global warming conditions. Meteorologische Zeitschrift 14:329-347

Philipp A, Della-Marta P, Jacobeit J, Fereday D, Jones P, Moberg A, Wanner H (2007) Long-term variability of daily North AtlanticEuropean pressure patterns since 1850 classified by simulated annealing clustering. J Climate 20:4065-4095

Philipp A, Bartholy J, Beck C, Erpicum M, Esteban P, Fettweis X, Huth R, James P, Jourdain S, Kreienkamp F, Krennert T, Lykoudis S, Michalides S, Pianko K, Post P, Álvarez DR, Schiemann R, Spekat A, Tymvios FS (2010) COST733CAT-a database of weather and circulation type classifications. Phys Chem Eart 35:360-373

Pinto JG, Ulbrich U, Leckebusch GC, Spangehl T, Reyers M, Zacharias S (2007) Changes in storm track and cyclone activity in three SRES ensemble experiments with the ECHAM5/MPI-OM1 GCM. Clim Dyn 29:195-210

Qi Y (2008) Bootstrap and empirical likelihood methods in extremes. Extremes 11:81-97

Räisänen J (2007) How reliable are climate models? Tellus A 59:2-29

Räisänen J, Hansson U, Ullerstig A, Döscher R, Graham LP, Jones C, Meier HE, Samuelsson P, Willén U (2004) European climate in the late twenty-first century: regional simulations with two driving global models and two forcing scenarios. Clim Dynam 22:13-31 
Roeckner E, Baeuml G, Bonaventura L, Brokopf R, Esch M, Giorgetta M, Hagemann S, Kirchner I, Kornblueh L, Manzani E, Rhodin A, Schlese U, Schulzweida U, Tompkins A (2003) The atmospheric general circulation model ECHAM5. Part I: model description. Max Planck Institute for Meteorology Report no. 349, Hamburg

Roeckner E, Brasseur G, Giorgetta M, Jacob D, Jungclaus J, Reick C, Sillmann J (2006) Climate projections for the 21 st century. MaxPlanck-Institut fuer Meteorologie, Hamburg

Saaroni H, Halfon N, Ziv B, Alpert P, Kutiel H (2009) Links between the rainfall regime in Israel and location and intensity of Cyprus lows. Int J Climatol 117:715-747

Salomon S, Qin D, Manning M, Chen Z, Marquis M, Averyt K, Tignor M, Miller H (eds) (2007) Climate change 2007-the physical science basis: contribution of Working Group I to the Fourth
Assessment Report of the Intergovernmental Panel on Climate Change. Cambridge University Press, Cambridge

Trenberth KE (2011) Changes in precipitation with climate change. Clim Res 47:123-138

Trigo I, Bigg G, Davies T (2002) Climatology of cyclogenesis mechanisms in the Mediterranean. Mon Weath Rev 130:549-569

Wijngaard JB, Klein Tank AMG, Konnen GP (2003) Homogeneity of 20th century European daily temperature and precipitation series. Int J Climatol 23:679-692

Zorita E, von Storch H (1999) The analog method as a simple statistical downscaling technique: comparison with more complicated methods. J Climate 12:2474-2489

Zwiers F, Ross RH (1991) An alternative approach to the extreme value analysis of rainfall data. Atmos - Ocean 29:437-461 